\title{
HAM dalam Wacana: Pro-Kontra dari Masa ke Masa
}

\author{
HS. Brodjo Sudjono
}

\begin{abstract}
Human rights history and development experiencing many descends and ascends. This phenomenon can not expelled from social and political conditon at that moment. In this modem era, human rights is entering third generation, where human rights no lenger viewed merely from political, economy, social and vulture perspective, ut more as universal solidarty rights even thought in reality this third generation still retain numcrous problems.
\end{abstract}

\section{Pendahuluan}

Dalam negara modem, hak asasi manusia' (HAM) merupakan salah satu institusi hukum yang sangat penting. Sistem hukum di negaranegara beradab ditandai oleh apresiasi yang tinggi terhadap HAM. HAM telah menjadi barometer peradaban hukum, karena disitu martabat manusia dengan manusia, dihormati dan dijunjung tinggi.
Sejumlah dokumen yang dikenal sekarang seperti: Universal Declaration of Human Rights, Intermational Covenant of Economic, Social, and Cultural Rights, The International Covenant on Civil and Political Rights, dan The Optional Protocol to The Intemational Covenant on Civil and political Rights, secara kolektif merupakan "Pemyataan Hak Asasi

\footnotetext{
'Dalam kepustakaan filsafat, teori dan ilmu hukum, terdapat dua istilah baku yang secara umum sering dianggap sama, tełapi sebenarnya memiliki makna yang berbeda, yakni hak-hak dasar (fundamental rights), dan hak-hak (asasi) manusia (human rights). Menurut Meuwissen seperti dikutip Abdul Gani, hak-hak (asasi) manusia memiliki pengertian yang sangat luas, baik yang bersangkut paut dengan wilayah berlakunya maupun menyangkut konotasinya. Hak-hak (asasi) manusia menunjuk pada hak-hak yang memperoleh pengakuan secara internasional, atau hak-hak yang dibela dan dipertahankan secara internasional. Sebaliknya, hak-hak dasar hanya dan selalu dikaitkan dengan negara bangsa (nation state), dalam arti hak-hak yang diakui oleh dan melalui hukum nasional negara tertentu. Lihat Abdul Gani, Hak-hak Manusia dan Mutu Manusia Indonesia, Makalah pada SeminarNasional mengenai Hak-hak Asasi Manusia, Semarang 25 Januari 1993, hlm. 2.
} 
Manusia internasional dan Universal" yang berfungsi sebagai batu uji bagi setiap negara beradab dalam menginterpretasikan ketetapan-ketetapan Piagam PBB mengenai hak asasi manusia. Tetapi bagaimanakah proses historis dari apa yang sekarang diterima sebagai "Pernyataan HAM Semesta" itu? Tulisan ini hendak mengurai dalam garis besarnya tonggak-tonggak wacana tentang HAM hingga ter-crystallized dalam dokumendokumen intemasional yang dikenal sekarang.

\section{Cikal Bakal HAM: Yunani dan Romawi Kuno}

Ihwal asal-usul HAM, para ahli umumnya mengaitkan dengan sejarah Yunani dan Romawi kuno. Hal itu didasarkan pada asumsi bahwa ide hak asasi manusia berkaitan erat dengan doktrin-doktrin hukum alam pramodern dari Stoicisme Yunani (Mazhab filsafat yang didirikan oleh Zeno dari Citium), yang beranggapan bahwa suatu kekuatan universal meliputi semua ciptaan, dan oleh karena itu tindak-tanduk manusia hendaknya dinilai dan diselaraskan dengan hukum alam. ${ }^{2}$

Hukum Romawi lewat lus Gentium, juga dilihat sebagai pengakuan eksistensi hukum alam dalam semangat yang sama dengan Stoicisme Hellenistik Yunani. lus Gentium (= hukum bangsa-bangsa), dilihat sebagai pengakuan hak asasi universal tertentu yang meluas melebihi hak warga negara Roma. Uipian, seorang hakim Romawi berkata demikian: "hukum alam adalah hukum yang alami-bukan dibuat negara, yang diperuntukkan bagi semua makhluk manusia, baik warga Roma maupun warga nonRoma".,

\section{Magna Charta: Dokumen Awal}

Salah satu tonggak yang mengungkapkan HAM secara tersurat, terjadi pada tanggal 19 Juni 1215 di padang rumput Runnymede, ketika Raja John menandatangani dokumen yang kemudian dikenal sebagai Magna Charta, atas tuntutan para baron Inggris. Kemudian pada tahun 1689 , seabad sebelum Revolusi Perancis meletus, parlemen Inggris mengesahkan Undang-undang tentang Hak (The Bill of Rights). Tetapi dokumen yang menjadi cikal bakal dari apa yang sampai sekarang diterima sebagai pernyataan HAM, baru dirumuskan hampir seratus tahun kemudian oleh Thomas Jefferson. Itulah Pemyataan Kemerdekaan (Declaration of Independence) Amerika, yang disetujui oleh Konggres Kontinental II pada tanggal 4 Juli 1776.

Tiga belas tahun kemudian, gagasan tentang HAM terhablur dalam "Undangundang Amerika tentang Hak" (American Bill of Rights). Dalam waktu yang hampir bersamaan, Perancis membuat "Deklarasi Hak Manusia dan Warga Negara Perancis" (Declaration of The Rights of Man and of The

\footnotetext{
¿Lihat Burn H. Weston, "Hak-hak Asasi Manusia", T. Mulya Lubis (penyunting), Hak-hak Asasi Manusia dalam Masyarakat Dunia : Isu dan Tindakan (Jakarta: Yayasan Obor Indonesia, 1993), hlm. 2.

${ }^{3}$ Ide ini juga dapat ditemukan pada pemikiran para pelopor Hukum Internasional seperti F. de Victoria, Hugo Grotius, dan E. de Vattel. Lihat dalam Kartini Sekartadji, "Implementasi Perjanjian Internasional mengenai Kejahatan tehadap HAM dalam Pembaharuan Hukum Pidana Indonesia", Thesis pada Program Pascasarjana UNDIP, 1994. Hal. 76 (tidak dipublikasikan)
} 
Citizen). Thomas Jefferson, yang waktu itu menjadi duta besar Amerika yang pertama di Perancis, dan Marquis de Lafayette, nagarawan Perancis, memainkan peran amat penting dalam kelahiran dua dokumen itu. Kedua dokumen tersebut dimaksudkan untuk mematrikan "hak-hak manusia yang kodrati, kudus, tak teralihkan untuk selamanya" pada persada politik modern. Inilah konsepsi modernis mengenai hukum -alam yang mengimplikasikan hak-hak alamiah abad XVII dan XVIII. ${ }^{4}$

\section{Pasca Abad Pertengahan: Dari Kewajiban ke Hak}

Selepas abad pertengahan, doktrin hukum alam mulai dikaitkan dengan teori-teori politik liberal mengenai hak-hak alamiah. Perdamaian Westpalia-masa kejayaan Renaissance, dan merosotnya feodalisme, oleh para ahli dilihat sebagai wujud nyata tuntutan terhadap hak asasi manusia (hukum alam) untuk dijadikan sebagai kebutuhan dasar sekaligus menjadi realitas sosial yang umum. ${ }^{5}$ Selama periode ini terjadi pula pergeseran cara pandang terhadap status hukum alam, dari hukum alam sebagai kewajiban (bagi penguasa dalam memerintah), kepada hukum alam sebagai hak yang harus dimiliki rakyat.
Inti dari semua ajaran serta ketentuan itu adalah, bahwa makhluk manusia dikaruniakan hak-hak yang kekal dan tidak dapat dicabut, yang tidak pernah ditinggalkan ketika umat manusia "beralih" untuk memasuki era baru dari kehidupan pramodern ke kehidupan modern, serta tidak pernah berkurang karena tuntutan "hak Illahi pada Raja". ${ }^{6}$ Konsepsi ini berbeda dengan konsepsi abad pertengahan, yang menganggap hukum alam sebagai manifestasi dari rencana IIlahi atau kebijaksanaan Illahi. Dengan diilhami semangat Aufklarung yang antroposentris, konsepsi hukum alam abad XVII dan XVIII justru bertumpu pada diri manusia, yakni rasio manusia.' Ekspresi yang lebih komprehensif terhadap pengagungan humanitas, tidak terlepas dari pencapaian-pencapaian ilmiah dan intelektual abad XIX lewat penemuan Galileo dan S.I. Newton, materialisme Thomas Hobbes, rasionalisme dualistik Rene Descartes, dan empirisme Francis Bacon dan John Locke.

John Locke yang dianggap sebagai teoritis hukum alam terkemuka pada zaman modern, dalam tulisan-tulisan yang berkaitan dengan Revolusi Inggris (Glorius Revolution) tahun 1688, mengatakan bahwa hak-hak asasi tertentu sedah jelas dengan sendirinya mengenai individu-individu sebagai makhluk

\footnotetext{
4Walaupun abad XVII di Eropa sudah banyak orang berpikir dan berbicara tentang hak-hak alamiah tetapi de facto secara konstitusional hak-hak tersebut pertama-tama ditetapkan dalam Unanimous Declaration of Independence of America. Lihat A. Gunawan Setiarja, "Menjajagi Pengertian HAM secara Filsafati", Makalah dalam Seminar Nasional Hak-hak Asasi Manusia, Semarang, 25 Januari 1993, hlm. 7.

${ }^{5}$ Burn H. Weston, op cit, hlm. 3.

${ }^{6}$ Sejarah telah mencatat bahwa tonggak pertama bagi kemenangan hak asasi terjadi di Inggris yaitu dengan lahirnya Magna Charta.

${ }^{7}$ Grotius memakai istilah ius hominis (hukum manusia). Hukum manusia itu berhubungan dengan hukum alam hanya karena ia adalah manusia. Setiardja, op cit, him. 7 .
} 
manusia karena hak asasi itu hadir dalam "keadaan alamiah" sebelum umat manusia menjadi masyarakat beradab. Hak-hak tertentu yang dimaksud terutama adalah hak asasi atas kehidupan, kebebasan/kemerdekaan dari pemerintah yang sewenang-wenang, serta hak milik. ${ }^{8}$ Perpaduan dinamika intelektual liberal ini dengan Glorius Revolution dan pernyataan hak-hak asasi yang dihasilkannya, menurut Weston, berpengaruh besar terhadap dunia Barat di akhir abad XVIII dan awal abad XIX, sehingga menjadi justifikasi munculnya gelombang agitasi tentang kebebasan. ${ }^{9}$

Thomas Jefferson yang dapat dikategorikan sebagai penganut setia ajaran Locke dan Montesquieu, menegaskan bahwa orangorang senegaranya adalah rakyat mereka yang sedang menuntut hak-hak asasi mereka yang berasal dari hukum alam dan bukan sebagai anugerah kepala negara. Dalam Deklarasi Kemerdekaan 4 Juli 1776, Jefferson memberi ungkapan yang sangat puitis: "kami beranggapan bahwa kebenaran-kebenaran ini sudah nyata dengan sendirinya, bahwa semua manusia diciptakan sederajat, bahwa mereka dikaruniai oleh pencipta mereka dengan hak asasi tertentu yang tidak dapat dicabut, bahwa di antara hak-hak ini adalah kehidupan, kebebasan, serta mengejar kebahagiaan." Demikian pula dengan Marquis de Lafayette yang meniru pernyataan-pernyataan dalam revolusi Inggris dan Amerika menyatakan bahwa "manusia lahir tetap bebas dan sama di dalam hak". ${ }^{10}$

Pergeseran di Abad ke-19: Konservatisme

Di tengah-tengah dominasi penganjur hak-hak asasi manusia sebagai hak alamiah, muncul pula pencela-pencela yang tidak kalah vokalnya. Titik serang mereka adalah doktrin tentang absolutisme hak-hak alamiah. Edmund Burke mengutuk absolutisme karena menurutnya, tuntutan publik terhadap hak-hak alamiah akan menimbulkan pergolakan sosial. Dalam kaitan dengan Declaration of The Rights of Man and of The Citizen, Burke mengritik para penyusun deklarasi tersebut dengan mengatakan bahwa mereka telah mempromosikan "fiksi yang menakutkan" mengenai persamaan manusia, yang hanya berfungsi mengilhami ide-ide yang tidak benar dan harapan-harapan yang sia-sia pada manusia yang telah ditakdirkan untuk menjalani perjalanan kehidupan yang tidak jelas dengan susah payah. Sementara itu, Jeremy Bentham, pendiri utilitarianisme itu, mengatakan, bahwa hak adalah "anak hukum", dari hukum yang nyata muncul hak-hak yang nyata, tetapi dari hukum-hukum yang imajiner, yakni hukum alam, muncul hak-hak yang imajiner pula. Menurutnya, hak alamiah adalah omong kosong sederhana; hak-hak alamiah yang tidak dapat dicabut (suatu ungkapan Amerika) adalah omong kosong yang retorik, omong kọsong di atas jangkauan. ${ }^{11}$

'Bum H. weston, op cit, hlm. 4.

भibid, hlm. 5.

10 bid.

"Serangàn terhadap hukum alam dan hak-hak alamiah ini, dengan demikian dimulai sejak akhir abad XVIII dan menjadi intensif serta meluas pada abad XIX dan awal abad XX. J.S. Mill, F.K. von Savigny, S.H. Maine, dan John Austin, untuk menyebut beberapa nama, merupakan pengkritik terhadap absolutisme hak-hak alamiah. Weston, op. cit, hlm. 6-7. 
Dostoyevsky, melalui tokoh "Sang Penyidik Agung" (The Grund Inquisitor) dalam novelnya "Kamarasov Bersaudara" (1881), berkata: Kalian memasuki dunia yang menjajikan kebebasan yang bahkan tidak dapat dipahami orang dalam kebersahajaan dan ketidakpatuhan. Nah, sekarang, katanya orang lebih bebas dari sebelumnya, namun mereka telah membawa kebebasannya kepada kami, dan dengan sopannya meletakannya di bawah telapak kaki kami. Mereka meraung dan memohon kepada kami: Kami kembali kepadamu; selamatkanlah kami dari diri kami sendiri!"12

Dari "kubu kiri", Karl Marx dalam eseinya tahun 1840, mengatakan bahwa: "deklarasi HAM ala Amerika dan Perancis itu bagaikan selembar ijazah yang menerangkan bahwa pemegangnya siap untuk terjun ke dalam peperangan satu lawan satu", ":.....HAM adalah tak lebih dari hak-hak seorang warga masyarakat beradab, yakni hak seorang egois yang terpisah dari orang-orang lainnya dan dari masyarakat.... tersedot ke dalam dirinya sendiri, sepenuhnya sibuk dengan kepentingan pribadinya, dan bertindak sesuai dorongan impulsifnya sendiri". ${ }^{13}$

\section{Seabad Kemudian: Prograsif Lagi}

Walaupun masa jaya hak-hak alamiah telah berlalu, namun ide tentang hak asasi manusia tetap bertahan. Penghapusan perbudakan, pembuatan undang-undang pabrik, pendidikan rakyat, serikat buruh, dan gerakan hak pilih yang universal merupakan contoh dan sekaligus asalnya yang transempirik telah menjadi skeptisisme umum. Lebih lagi setelah kebangkitan dan kerunfuhan Nazi, Jerman, ide tentang hak asasi manusia mendapat penghargaan yang selayaknya. Hukum yang mengesahkan pemusnahan orang-orang Yahudi dan kaum minoritas yang alin justru dilihat sebagai pelanggaran hak asasi manusia yang keji, sehingga persoalan HAM tidak dapat didasarkan pada doktrindoktrin utilitarian murni, idealis, ataupun kedaulatan pemerintah.

Dewasa ini, mayoritas cendekiawan hukum, filsuf, dan kaum moralis setuju bahwa, terlepas dari budaya peradaban, setiap makhluk manusia berhak, paling tidak dalam teori, atas sebagian hak asasi. Louis Henkin, cendekiawan hak-hak asasi manusia, pernah mengatakan bahwa: "penerimaan yang pada pokoknya universal terhadap hak-hak asasi manusia pada prinsipnya sedemikian rupa sehingga tidak ada pemerintah yang berani membangkang terhadap ideologi hak asasi manusia dewasa ini. ${ }^{14}$

Paruh terakhir abad XX, dapat dikatakan sebagai puncak lahirnya pengakuan intemasional dan universal terhadap hak asasi manusia. Dalam traktat pembentukan Perserikatan Bangsa-bangsa, semua anggota berjanji untuk melakukan tindakan bersama dan terpisah untuk pencapaian penghomatan universal dan ketaatan terhadap hak asasi manusia dan kebebasan yang fundamental

12M.Berman, Modemism and Human Rights Near The Millenium (Dissent: Summer, 1995), hlm. 333-341. 13/bid, hlm. 339.

14Weston, op. cit., him. 7. 
bagi semua tanpa perbedaan ras, seks, bahasa atau agama. ${ }^{15}$ Melalui Deklarasi Universal Hak-hak Asasi Manusia (1948), yang kemudian dikenal dengan UDHR, para wakil bangsabangsa yang beraneka budayanya mengakui hak-hak asasi yang tercantum di dalamnya, "sebagai tolok ukur pencapaian bersama bagi semua rakyat dan semua bangsa". Hak-hak tersebut secara kategorial dapat digolongkan menjadi enam kategori:

1. Hak asasi pribadi (personal rights), yang meliputi kebebasan menyatakan pendapat, kebebasan memeluk agama, kebebasan bergerak dan sebagainya;

2. Hak-hak asasi ekonomi (property rights), yaitu hak untuk memiliki sesuatu, membeli dan menjual serta memanfaatkannya;

3. Hak-hak asasi politik (political rights), yaitu hak untuk ikut serta dalam pemerintahan, hak pilih (dipilih dan memilih dalam suatu pemilihan umum), hak untuk mendirikan partai politik dan sebagainya;

4. Hak-hak asasi untuk mendapatkan perlakuan yang sama dalam hukum dan pemerintahan atau (rihgts of legal equality);

5. Hak-hak asasi sosial dan kebudayaan atau social and culture. Umpamanya hak untuk memilih pendidikan, hak untuk mengembangkan kebudayaan dan sebagainya;

6. Hak asasi untuk mendapatkan perlakuan tata cara peradilan dan perindungan (procedural rights). Misalnya peraturan dalam hal penahanan, penangkapan, penggeledahan, peradilan dan sebagainya. ${ }^{16}$

Piagam Perserikatan Bangsa-bangsa (1945), diawali dengan penegasan kembali suatu "kepercayaan terhadap hak-hak asasi manusia, martabat dan nilai pribadi manusia, hak asasi yang sama anatara laki-laki dan perempuan, ${ }^{17}$ serta kesederajatan antara

${ }^{15}$ Sesudah Perang Dunia II, komunitas bangsa-bangsa yang sebagian besar dilhami oleh semangat Komisi Palang Merah Internasional menandatangani serangkaian deklarasi dan konvenan multilateral yang dimaksudkan untuk meredakan sikap permusuhan, melindungikorban-korban peperangan. Sekitar masa yang sama, mula-mula dengan dua konvensi buruh multilateral yang ditandatangani pada tahun 1906, dan kemudian - dengan inisiatif. Organisasi Buruh Internasional (ILO-1909), sebuah komunitas internasional yang diarahkan untuk mempromosikan hak-hak asasi manusia. Langkah-langkah organisasi ini tidak saja terbatas pada bidangbidang tradisional berkaitan dengan hukum dan hubungan perburuhan (misalnya: kesehatan buruh, keamanan, sertakesejahteraan di bidang industri), tetapi juga, terlebih sesudah Perang Dunia II memusatkan perhatian kepada hak-hak asasi lainnya, yaitu: kerja paksa, diskriminasi dalam pekerjaan dan mata pencaharian, kebebasan behimpun untuk melakukan tawar menawar secara kolektif dan upah yang sama untuk pekerjaan yang sama (lbid).

${ }^{16}$ Ramdhon Naning, Cita dan Citra Hak-hak Asasi Manusia dilndonesia (Jakarta: Lembaga Kriminologi Universitas indonesia Program Penunjang Bantuan Hukum Indonesia, tt), hlm. 17; Bandingkan dengan R.B. Lilich, "Civil Rights", telah diterjemahkan dalam Bahasa Indonesia oleh A. Setiawan Abadi, "Hak-hak Sipil", Dalam Weston, op. cit, him. 69-86.

${ }^{17}$ Istilah Human Rights (= hak-hak asasi manusia) pertama kali dikemukakan oleh E. Roosevelt untuk menggantikan istilah The rights of Man, ketika ia bertindak sebagai Ketua Komisi HAM PBB dalam rangka merumuskan Universal Declaration of Human Rights tahun 1948. Penggantian istilah fights of Man oleh karena istilah tersebut selalu diucap senafas dengan semangathukum alam dan tidak mencakup The rights of Woman. Lihat T. Mulya Lubis, "Dilema Pencariam Hak Asasi Manusia dalam Sejarah Indonesia Merdeka", Makalah dalam Diskusi LBH 18 Maret 1991, hlm. 4. 
bangsa-bangsa, baik yang besar maupun yang kecil.

Oleh karena UDHR dinilai hanya menekankan hak-hak yang bersifat politis, dan tidak mengandung kewajiban-kewajiban hukum yang dapat dipaksakan, maka pada tahun 1966 dalam sidang umum PBB disahkan dua kovenan yang secara hukum akan mengikat negara-negara anggota PBB yang menandatangani dan meratifikasinya. Kedua kovenan tersebut adalah International Covenant on Econimic, Social and Cultural Rights; dan The Intemational Covenant on Civil and Political Rights, yang dilengkapi oleh satu instrumen yang dikenal dengan nama The Optional Protocol to The Intemational Covenant on Civil and Political Rights.

Untuk masa sekarang UDHR dan dua kovenan di atas, secara kolektif dikenal sebagai "pemyataan Hak-hak Asasi Manusia Internasional dan Universal" yang berfungsi sebagai batu ujian (= tolok ukur) untuk menginterpretasikan ketetapan-ketetapan Piagam PBB mengenai hak asasi manusia. Di lingkungan regional bangsa-bangsa Asia Afrika, muncul sejumlah piagam HAM yang mencerminkan semangat perjuangan HAM bangsa-bangsa tersebut. Di sini dapat dicatat, misalnya Africa Charter on Human People's Rights (Banjul Charter, mulai berlaku 1986), Cairo Declaration on Human Rights in Islam (1990), Singapore White Paper of White Shared Values (1991), dan The Kualalumpur Declaration of Human Rights by AIPO (1993).

\section{Tiga Generasi HAM: Epilog}

Dalam pejjalanan sejarah sejak awal abad modern hingga kini, ruang lingkup konsep hak asasi manusia telah berkembang seturut pergumulan atau tuntutan zaman, baik dalam subtansi maupun bentuknya. Karel Vasak, ahli hukum Perancis telah mengklasifikasikan atau lebih tepat mempolarisasi "tiga generasi" mengenai mazhab-mazhab pemikiran dan tindakan yang dominan menyangkut hak-hak asasi manusia. ${ }^{18}$

Generasi pertama berupa tuntutan akan hak-hak kebebasan sipil dan politik yang cikal bakalnya berasal dari teori-teori reformis abad 17 dan 18. Generasi ini mengartikan hak asasi manusia sebagai pembebasan dari intervensi penguasa dalam pencarian martabat manusia. Nilai sentral dan konsepsi generasi pertama tentang hak asasi manusia adalah kebebasan (liberty), sebagai suatu perisai yang melindungi individu dari penyelewengan dan penyalahgunaan otoritas politik. Konsepsi hak asasi seperti ini sering dilabelkan sebagai konsepsi liberal-barat.

Generasi Kedua berupa tuntutan akan hak-hak ekonomi, sosial dan budaya yang bersumber terutama dari tradisi sosial dan budaya yang berakar dalam tradisi sosialis, dan secara revolusioner diperjuangkan untuk mementahkan intervensi atau pengaruh kapitalis dan kebebasan individu yang mendasarinya dalam mengekploitasi kelas pekerja dan rakyat-rakyat daerah jajahan. Nilai sentral dari hak-hak asasi generasi kedua pada prinsipnya adalah tuntutan bagi persamaan sosial yang universal.

${ }^{18}$ Lihat Weston, op.cit, him. 12-17. 
Generasi Ketiga berupa tuntutan akan hak-hak solidaritas kemanusiaan yang universal (mondial). Hak-hak solidaritas kemanusiaan yang universal dimaksud antara lain tuntutan adanya pemerataan kekuasaan, kekayaan serta hak untuk berpartisipasi dalam pemanfaatan warisan bersama umat manusia (sumber daya bumi dan ruang angkasa, informasi dan kemajuan ilmiah, tradisi dan lain-lain). Empat hak-hak asasi yang tercakup pula dalam tuntutan generasi ketiga adalah hak atas penentuan nasib sendiri dalam bidang politik, ekonomi, sosial dan budaya; hak atas lingkungan hidup yang sehat dan seimbang; dan hak atas bantuan bencana alam yang bersifat kemanusiaan.

Cuma persoalannya sekarang adalah, terdapat sejumlah masalah mendasar belum disetujui secara penuh sebagai ruang lingkup substansif hak asasi manusia yang universal. Masalah-masalah dimaksud antara lain: (1) Apakah hak asasi manusia merupakan pemberian hak IIlahi, moral atau hukum? (2) Apakah hak asasi manusia disahkan dengan intuisi, kebiasaan, teori kontak sosial, asas keadilan distributif, atau sebagai prasyarat bagi kebahagiaan? (3) Apakah hak asasi manusia akan dianggap tidak dapat ditarik kembali, atau untuk sebagian dapat ditarik kembali? (4) Apakah hak asasi manusia akan luas atau terbatas dalam hal jumlah dan isi?'19 Tidak ada jawaban yang pasti dan mengikat untuk semua masalah itu. Derajat komitmen pada HAM, akan ditentukan jawaban yang tepat bagi bangsa dan negara ini.

\section{Simpulan}

Sejarah dan perkembangan HAM pada perjalannya mengalami pasang surut. Hal ini tidak terlepas dari kondisi sosial politik kala itu. Namun demikian, pada era modern ini HAM sudah berada pada generasi ketiga, yaitu HAM tidak saja dipandang dari politik, ekonomi sosial dan budaya. Namun HAM saat ini dipandang sebagai hak-hak solidaritas universal. Walaupun dalam kenyataannya generasi ketiga ini masih menyimpan sejumlah masalah.

\section{Daftar Pustaka}

Abdul Gani, Hak-hak Manusia dan Mutu Manusia Indonesia, Makalah pada Seminar Nasional mengenai Hak-hak Asasi Manusia, Semarang 25 Januari 1993.

Burn H. Weston, "Hak-hak Asasi Manusia", T. Mulya Lubis (penyunting), Hak-hak Asasi Manusia dalam Masyarakat Dunia: Isu dan Tindakan (Jakarta: Yayasan Obor Indonesia, 1993).

Kartini Sekartadji, "Implementasi Perjanjian Internasional mengenai Kejahatan terhadap HAM dalam Pembaharuan Hukum Pidana Indonesia", Thesis pada Program Pascasarjana UNDIP, 1994.

A. Gunawan Setiarja, "Menjajagi Pengertian HAM secara Filsafati", Makalah dalam Seminar Nasional Hak-hak Asasi Manusia, Semarang, 25 Januari 1993.

M.Berman, Modernism and Human Rights Near The Millenium (Dissent: Summer, 1995).

19/bid, hal. 10. 
- Ramdhon Naning, Cita dan Citra Hak-hak Asasi Manusia di Indonesia (Jakarta: Lembaga Kriminologi Universitas Indonesia Program Penunjang Bantuan Hukum Indonesia, tt).
T. Mulya Lubis, "Dilema Pencarian Hak Asasi Manusia dalam Sejarah Indonesia Merdeka", Makalah dalam Diskusi LBH 18 Maret 1991.

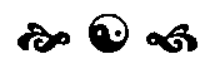

